\title{
METHODOLOGICAL DESIGN OF ACTION FOR MILITARY STUDENTS, IN VIEW OF FACILITATING THE PHYSICAL TRAINING OBJECTIVES
}

\author{
Fabiana MARTINESCU-BĂDĂLAN \\ "Nicolae Bălcescu" Land Forces Academy, Sibiu, România \\ martinescu fabiana@yahoo.com
}

\begin{abstract}
For us, didactic design is a process that provides the contents, objectives, methods and means of training of military students for their assessment. As in any training, we were forced to think about their needs in order to be able to work out the work schedules. In order to obtain high results in the activity of subjects we need objectives of general and specific physical training as well as psychomotric training.
\end{abstract}

KEYWORDS: curriculum, physical training, military, goals, contents

\section{Introduction}

The main purpose of this work program is to support the central process of combination between military students' psyche and body motion through movement.

We have found that young people today are moving away from what means "control", co-ordination or efficiency which signifies the movements performed in various forms of gymnastic performances (Macovei and Vasile, 2009).

The curriculum seeks to help individuals form and differentiate general orientation and control of movements, to be able to direct their energy to the right place and time, with varying degrees of conscious direction.

The curriculum seeks to transform the activity of organizing movements, bringing inward mobility to thought, sensitivity and will, but preventing a complete expression of the individual's intent. The curriculum supports the psycho-motric development pathway of military students.

The general and specific skills and also the contents are reported at a time allocated on average to 2-3 trainings per subject per week. We thought this should be possible for subjects who have one military training day and classes for the rest of the week.

The time allocated to this curriculum offers the opportunity to consolidate and refine the skills, the physical customs and abilities, previously acquired through their concentric resuming, contributing to the goals of increasing the physical and psycho-motric training level.

The specific abilities and contents mainly aim at achieving the ability of subjects to practice exercises to improve 
general and specific physical capacity for optimal movement in the field as well as psycho-motric skills through specific means.

The contents of the curriculum can be made in various forms and aspects, given that the Land Forces Academy has almost the best material resources.

During cold weather, or if atmospheric conditions do not allow the performance of military physical education lessons in the designated sports area, classes can be made at the gym or at the swimming pool. The organization of the groups within the thematic walks is recommended to be done by respecting the work circuit, each workshop developing a physical skill, through a number of repetitions corresponding to the possibilities of the individuals and the stage of training in which they are located.

The precise perception of spatial parameters (distance, shape, direction, depth) contributes directly to the formation of the bodily scheme as an image of the body, its place in space and its possibilities for movement (Lazon, 1990, cited by Horghidan, 2000).

In order to develop every physical quality and to educate physical skills and abilities, a large number of specific exercises have been tested and used, aiming at achieving a specific driving technology.

\section{Didactic Design to Achieve} Training Objectives (Martinescu, 2014)

Operational structures for general physical training

Framework training objectives: capacity;

- Development of general physical

- Maintaining the state of health and increasing the ability to adapt to various conditions;

- Development of team spirit;

- Improving the functioning of all body systems;
- Analytical development of the muscles of the upper limbs and lower limbs

- Analytical development of back and abdominal muscles;

Framework content for general resistance development (Martinescu, 2014):

$>$ long distance running $800-1000 \mathrm{~m}$., in uniform tempo; tempo:

Running alternating distances and

- distance $50 / 25 \mathrm{~m}$ - tempo $2 / 4$ and $4 / 4$;

- distance $100 / 50 \mathrm{~m}$ - tempo $1 / 2$ and $2 / 4$;

- distance $200 / 100 \mathrm{~m}$ - tempo $1 / 2$ and $2 / 4$.

Physical circuits.

Framework content for analytical development of upper limb muscles and lower limbs (Martinescu, 2014):

For upper limbs:

$>$ pushups standing with the hands on the ground; 2-4 series x 10 reps, 1 min pause;

$>$ pushups standing with the hands on the ground and the feet on a small bench; 2-4 series x 8 reps, 1 min pause;

$>$ pushups standing with the hands on the ground, clapping hands; $2-4$ series $\mathrm{x}$ 8 reps, 1 min pause;

For lower limbs:

squats with the hands on the head; 2-4 series X15 reps, 45 seconds pause;

squats with 2-3 kg dumbbells x 1520 reps, 50 seconds pause;

squats holding a bar (the bar should not exceed $8 \mathrm{~kg}$ ) x15 reps, 1 minute pause;

$>$ feints, hands behind the back; 2-4 series $x 12$ reps, 45 seconds pause;

$>$ rope jumps, 3-5 series x 30 reps, 45 seconds pause; 
Framework content for the analytical development of abdominal and back muscles (Martinescu, 2014):

For abdominal muscles:

$>$ lying on the back, legs folded trunk lifting; 3-5 series x 15 reps, 1 min pause;

lying on the back - lifting the legs to the vertical and lowering them without touching the ground; 3-5 series $\mathrm{x}$ 20", 1 min pause;

lying on the back - lifting the feet at $45^{\circ}$ and moving them up and down; 3-5 series x 20", 1 min pause;

lying on the back - simultaneous lifting of legs and trunk; 3-5 series x 10 reps, 1 min pause;

$>$ lying on the back, feet left up at $90^{\circ}$, lifting hands and trunk touching the toes and return; 3-5 series $\mathrm{x} 15$ reps, 1 min pause;

hanging at the wall bars - lifting the knees to the chest and lowering them; 3-5 series x 15 reps, 1 min pause;

$>$ lying on the back, arms around the body - lifting legs and carrying them over the head, until the toes reach the ground and return; 2-4 series x 10 reps, 1 min pause;

For back muscles (Martinescu, 2014):

$>$ seated with legs stretched forward, with backrest restraint, lifting of the basin in extension, head on the back and return; 3-4 series x 10 reps, 30" pause;

lying forward with hands on your neck - arcing the trunk back; 3-4 series $\mathrm{x} 10$ reps, 1 min pause;

$>$ lying forward, alternate lifting of legs and trunk in extension with running on the abdomen; 3-4 series $\times 10$ reps, 1 min pause;

hanging on the wall bars extension of the trunk leading the legs as far back as possible; $2-4$ series $x 10$ reps, 1 min pause; throwing the medical ball back with two hands through the extension of the trunk; 3-4 series $x 10$ reps, 1 min pause;

Operational structures for specific physical training (Martinescu, 2014):

Framework training objectives:

- developing reaction and execution speeds at different stimuli;

- developing motion speed with starting points from different positions;

- developing speed resistance.

Framework content for speed and skill development (Martinescu, 2014):

$>$ Exercises specific to athletic tests (ankle jogging, back-kneeling jogging, swinging legs forward, high knee skips, crossing step)

Applicative runs (timed)

Movements, stops and changes of direction, made quickly to different visual and audio stimuli.

Throwing and gripping of objects, combined with certain exercises of attention.

Repeating some technical procedures specific to body-to-body combat in shorter time units.

$>$ Breaks of rows and regroups in different bands.

$>$ Sitting with a weapon held horizontally forward, releasing and catching it before it touches the ground.

Walking on a straight line or zigzag with eyes closed.

Walking on toes or squatting on the gym bench (can be done forwards or backwards)

Throwing a small object into the air, rolling forward from squatting into squatting (or rolling on the shoulder) and gripping that object before it touches the ground.

Throwing a hand grenade into the air with the simultaneous movement between the randomly arranged poles. 
Running with rhythm change $2 \times 9$ minutes, tempo $2 / 4-1$ minutes, $4 / 440$ seconds, this rhythm alternates for 9 minutes, pause between repetitions 2 minutes;

$>$ Exercise for repeated speeding: runs at 50,40,30, 20,10m distances, and each length is repeated in tempo speed $4 / 4$, as follows: $50 \mathrm{~m} \mathrm{x} \mathrm{1;} 40 \mathrm{~m} \mathrm{x} \mathrm{2;30} \mathrm{m} \mathrm{x} \mathrm{3;}$ $20 \mathrm{~m} \times 4 ; 10 \mathrm{~m} \times 5$. The exercise is repeated twice with a 2-minute pause;

$>$ "Oregon" exercise is as follows: running in tempo $3 / 4100 \mathrm{~m}$, after which the execution for 30 seconds of some driving structures (squats, abdomen, jumping on 2 legs, extensions, "frog jumps", planks, etc.) the exercise is performed by repeating the run and exercises 10 times. The recovery time between an "oregon" exercise and another is 2 minutes (https://learningcenter. fiba.com/FIBAiRef/lms/).

\section{Operational structures for psychomotor training}

Framework training objectives:

- Increased general physical coordinator;

- Increased ocular-physical coordination;

- Increased joint stability and mobility in order ensure their complete function;

- Educating the correct repositioning of the body (global and segmental), both in static positions and in motion.

Framework contents to increase joint stability and mobility (stretching exercises) (Martinescu, 2014):

Standing with your back straight and your hands free from your body; slightly bend the neck in front, approaching the chest and stay in this position 5-8 seconds. Repeat the movement 1-3 times, on the left and on the right.

Standing with your feet spread, arms over your head, gently grasp the left elbow with your right hand and pull it lightly, while bending the trunk on the right side; maintain the position for 10-12 seconds, then change the side; repeat the movement 2-3 times for each side;

Standing, supported with a hand on a wall, straight position of the back, grab your ankle on the same side with the other hand and gently pull it towards the bottoms; maintain the position for 10-12 seconds, and then change the hand and the leg; repeat the movement 2-3 times for each side;

Seated, with the right leg stretched and the left one bent over the right one, with the foot supported by the floor, parallel to the right knee; hold the knee of the left foot with your hands and pull to the right shoulder, hold the position for 10-12 seconds, then change; repeat the movement 2-3 times for each side;

Standing with your feet wide, feints are executed while maintaining the position for 10-12 seconds, then the leg is changed, repeating the movement 2-3 for each leg;

Depending on the distance, semifeints are executed while maintaining the position for 10-12 seconds for each leg; repeat the movement 2-3 for each leg;

Standing with your feet wide from a wall, bending the trunk by gripping the right foot at the ankle level with the hands and holding the position for 10-12 seconds, then changing the foot and maintaining the position; Repeat the movement 2-3 for each side;

Framework contents for psychomotric training (Martinescu, 2014):

From the standing position a jump is performed with a turn around the longitudinal axis of the body, to the left and to the right;

$>$ Balancing on one leg, holding the other with one hand on the back, on the gym bench;

Balancing on one leg on a $10-15$ cm strip, the other leg held by a hand at the back, (timed); 
Moving in different types of walks, made with the side, lateral, with the back towards the forward direction, with turns, steps over various obstacles, executed on the surfaces with bigger widths $(30-35 \mathrm{~cm})$ and low heights, movements by running are also carried out; then it is carried out on surfaces with increasingly smaller widths (10-15 cm);

Running movements, turning your look over the shoulder.

\section{Conclusions}

The purpose of this curriculum is only to help improve the level of physical training and maintain it. Taking into account that the exercises to develop skill and strength involve more complex anatomical positions, as well as intense neuromuscular connections and stresses, we have taken into account the principle of accessibility in the effort for these exercises.
In determining the degree of complexity of exercises and the density of solicitation, we took into account the training phase of the military students, approaching the exercises from simple to complex, from easy to difficult, from known to unknown.

This plan pursues several parameters to ensure the quality of the exercises, to diversify them and to fulfill all the framework objectives that we have set out.

For example, our subjects have a certain level of experience, and they are often able to adapt the exercises to their capabilities, as well as to their program.

Moreover, we must not forget that they every week they have one day of instruction as well as morning recreation exercises, which also contribute to maintaining an optimal tone.

We must understand that these working programs must be applied individually and according to the characteristics of each subject.

\section{REFERENCES}

Horghidan, V. (2000). Problematica psihomotricităţii, Bucureşti: Editura Globus, 55.

Macovei, S. \& Vasile, L. (2009). Bazele generale ale mișcării - fundamente în educarea motricităţii, Palestrica Mileniului III - Civilizaţie şi Sport, Vol. X, Nr. 3 (37), 313-317.

Martinescu, F. (2014). Arbitrajul în baschet - tendinţe şi strategii de optimizare a pregătirii şi prestaţiei arbitrilor divizionari " $A$ ", $\mathrm{PhD}$ Thesis, București: Universitatea Națională de Educație Fizică și Sport.

www.//learningcenter.fiba.com/FIBAiRef/lms/. 